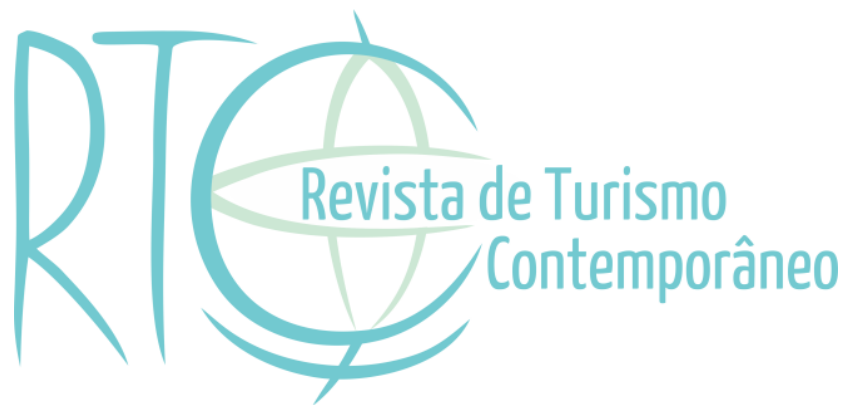

\title{
Apontamentos históricos sobre a profissão do guia de turismo
}

\section{Historical points on the profession of the tourism guide}

\section{Celso Maciel de Meira}

Professor (interino) do Curso de Turismo da Universidade do Estado de Mato Grosso UNEMAT, Nova Xavantina/MT, Brasil

E-mail: celsotour@gmail.com

\section{Elizabete Sayuri Kushano}

Professora Adjunta II do Curso de Tecnologia em Gestão do Turismo da Universidade Federal do Paraná - UFPR, Matinhos/PR, Brasil

E-mail: sayuritur@gmail.com

\section{Hélio Cesar Hintze}

Professor da Universidade Federal de São Carlos - UFSCar, São Carlos/SP, Brasil

E-mail: heliohintze@fazerpensar.com.br 


\section{RESUMO}

No decorrer da história, a profissão de guia de turismo se desenvolveu consideravelmente, tornando-se elemento agregador de qualidade do setor de serviços das atividades turísticas. Seguindo o percurso do tempo, este artigo tem como objetivo apontar questões históricas e aspectos legais sobre a formação e profissionalização do guia de turismo com enfoque no Brasil. Para tanto, como metodologia, ao recorte histórico que se propôs, foi utilizada a pesquisa do tipo bibliográfica e documental, que se valeu de recursos físicos e eletrônicos. A justificativa para tal pesquisa consiste na relevância desta profissão para o planejamento e gestão de atividades turísticas, além da escassez de estudos dessa natureza. A partir dessas investigações, apurou-se, dentre outras questões, que desde os primórdios da humanidade, sempre houve a presença de pessoas que guiassem grupos em situações diversas. No que concerne ao turismo contemporâneo, o guia de turismo, configura-se como a única profissão do trade turístico reconhecida e regulamentada por Lei, tendo, na prática, um importante papel na operacionalização de roteiros e na facilitação e mediação entre os elementos dos destinos e o turista, com vistas às experiências turísticas.

Palavras chaves: Apontamentos Históricos. Guia de Turismo. Profissão. Brasil.

\section{ABSTRACT}

In the course of history, the profession of tourism guide has developed considerably, becoming an aggregator of quality in the service sector of tourist activities. Following the course of time, this article aims to point out historical issues and legal aspects about the training and professionalization of the tourism guide with a focus in Brazil. In order to do so, as a methodology, to the historical cut that was proposed, the research of the bibliographic and documentary type was used, which was worth of physical and electronic resources. The justification for such research is the relevance of this profession for the planning and management of tourist activities, in addition to the shortage of studies of this nature. From these investigations, it was found, among other issues, that since the early days of humanity, there have always been the presence of people who have guided groups in different situations. As far as contemporary tourism is concerned, the tourism guide is set up as the only profession of the tourism trade recognized and regulated by law, having in practice an important role in the operation of roadmaps and facilitation and mediation between Elements of the destinations and the tourist, with a view to the tourist experiences.

Keywords: Historical Notes. Tour Guide. Profession. Brazil. 


\section{INTRODUÇÃO}

Estima-se que em 2030 haverá 1 bilhão e 800 milhões de turistas ao redor do mundo (OMT, 2017). De fato, tal número de elevada expressividade atesta o turismo como um dos maiores fenômenos sociais do século XXI, como também, atividade de impactos econômicos em escala mundial.

Crescente número de turistas são viajantes que organizarão e irão executar suas viagens de forma individual, sem a presença de agências de turismo emissivo e receptivo e sem a contratação de um guia de turismo. No entanto, outra parcela considerável, irá fazer uso desses serviços, considerando, por exemplo: a segurança, a confiabilidade, a comodidade, a interação cultural, entre outros fatores (Chang, 2014 \& Huang, 2010). Nesse sentido, auferindo à profissão de guia de turismo, sua importância; porém, buscando as adaptações face às mudanças e tendências de mercado.

Cabe conceituar o que é guia de turismo. Para Hintze (2007), ele é o cicerone dos turistas, sendo a única profissão do trade turístico regulamentada por lei e que requer a realização de um curso preparatório para que o profissional possa qualificar-se como guia de turismo (nas categorias Regional e Nacional, incluindo América do Sul). Para Trigo (1999), o guia de turismo é um profissional polivalente que participa da parte final (a execução) do longo processo pelo qual passa o produto turístico.

Neste artigo, cujo objetivo principal foi o de apontar questões históricas e aspectos legais sobre a formação e profissionalização do guia de turismo no Brasil, utilizou-se de pesquisa bibliográfica e documental como procedimentos metodológicos, valendo-se de recursos físicos e eletrônicos. Para tanto, embasou-se na proto história da profissão de guia de turismo e analisou-se documentos pertinentes à legislação do Setor.

A importância desta pesquisa se justifica para a busca de um melhor entendimento na construção de conhecimento sobre a profissão, perpassando a evolução histórica, os avanços e retrocessos na categoria e suas bases legais, além da escassez de estudos dessa natureza.

\section{HISTÓRICO SOBRE O DESENVOLVIMENTO DA PROFISSÃO DE GUIA DE TURISMO}

Devido às mais variadas demandas, a espécie Homo sapiens precisou, em diversos momentos, se deslocar. Uma vez que os humanos se deslocaram, não raro, precisaram de guias. O termo guia, de acordo com Sales (2012, p. 18), "significa o que dá orientação, encaminhamento, norteamento, luz, direção, mostra rumos a serem seguidos". 
Para Sigaux (1965), com base nos relatos de Heródoto (tido como o primeiro viajante da história), as atividades ligadas ao guiamento de pessoas teriam surgido acerca de 440 a.C. Todavia, os guias do tempo de Heródoto tinham funções diferentes dos profissionais contemporâneos. Não eram guias de turismo propriamente ditos, pois àquela época não se pode afirmar que houvesse turismo (não ao menos nos termos como o turismo contemporâneo é conhecido e com os quais serão conduzidas as análises deste trabalho). Estes guias conduziam exércitos em suas batalhas em territórios inimigos, operavam como facilitadores da comunicação (intérpretes) providenciavam transportes, meios de hospedagem e alimentação, dentre outras atividades ligadas à função (SENAC, 2002).

Tais guias, de acordo com Holloyway (1977) apud Rejowski (2002 p. 19), desempenhavam funções diversas:

Os periegitai tinham como função principal orientar os viajantes ao redor de sítios visitados, a exemplo do papel que desempenham os guias de turismo numa excursão ou num passeio pela cidade;

Os exegetai eram especialistas e conselheiros em assuntos religiosos e de rituais e tinham como missão prestar orientações religiosas aos visitantes.

Ainda, no sentido da orientação e de um contexto religioso,

[...] desde cedo, as estórias são desenvolvidas dentro de um contexto de narrativas, onde a estrela-guia conduz através de seus raios cintilantes, direcionando, irradiando energia, seduzindo e dando segurança. Na Bíblia, também no Novo Testamento, lêse o relato do fato de a estrela-guia ter guiado os três magos que visitariam o Menino Jesus recém-nascido. Na literatura do turismo, o guia de turismo pode ser visto como o anjo Rafael, que tão bem acompanhou o jovem Tobias à Média (lugar desconhecido, não conhecia os caminhos e por percalços que passaria), inspirandolhe confiança e segurança, além da grande aprendizagem que a viagem lhe proporcionara. (Sales, 2012, p.18)

Das histórias narradas e dos mitos de toda ordem, encontra-se referências à necessidade do guiamento, da condução. Isto se dá em todos os tempos e não é diferente na Idade Média. Depois de um período considerado inadequado para as viagens, particularmente, em função de segurança, retomou-se à prática das mesmas, ainda com destaque para aquelas de cunho religioso, que haviam sido consideravelmente diminuídas pela insegurança do período medieval (Ignarra, 2013).

Já na idade moderna, essas peregrinações se tornaram constantes (Ignarra, 2013), posto que neste momento da história, o guia estava encarregado de informar aos peregrinos sobre as cidades destino, assim como sobre as acomodações que poderiam encontrar pelas estradas utilizadas (Rejowski, 2002). 
Com as transformações ocorridas no século XVI, em um contexto de reforma protestante, houve uma mudança paradigmática em relação às questões de mundo. $\mathrm{O}$ pensamento se voltou para, dentre outras inquietações humanas, o interesse em conhecer o que estava além dos reinos em que se viviam. Ademais, havia uma cobrança da sociedade da época em relação ao aumento do repertório cultural das pessoas, principalmente as mais abastadas, que viam nas viagens formas de atender esses novos anseios. Na Inglaterra, para concretizar esses deslocamentos, necessariamente, os serviços de guiamentos foram bastante utilizados nas viagens denominadas Grand Tours (Montes, 2013).

De acordo com Urry (1991) apud Salgueiro (2002), ao final do século 17, o turismo era essencialmente praticado por filhos da aristocracia e da chamada gentry (pequena nobreza). Porém, aos poucos, essa clientela foi se ampliando, de modo que, ao final do século 18, o Grand Tour estava já firmemente estabelecido para os filhos da classe média urbana melhor situada, formada por burgueses prósperos e emergentes do setor de serviços que a indústria indiretamente engendrava.

Ressalta-se que neste período, ainda não se tinha as configurações da forma moderna de turismo conhecida. O turismo no contexto capitalista atual surge no século XIX, como será tratado no decorrer deste escrito.

Nesse sentido, em relação aos guias, eram ainda informalmente contratados pelo viajante, individualmente em cada lugar, e os guias impressos que surgiam possuíam ainda a forma de relatos de viagem ou de coleções de vistas de lugares, sem o formato dos guias atuais, bastante informativos e sistematizados em seções específicas para facilitar a consulta. Com o passar do tempo, o turismo aristocrático dos Grand Tours foi gradativamente gerando uma infraestrutura turística voltada ao seu público. Pouco a pouco as atividades de transporte, hospedagem e de guia foram se estruturando em serviços especializados, até se tornarem campos de atuação profissional, conduzidos por 'especialistas' (Salgueiro, 2002).

Considera-se importante mencionar algumas diferenças dessas viagens em relação àquelas praticadas no período medieval, que agrupavam viajantes para explorar, descobrir, adquirir conhecimentos e buscar outras culturas. Para essas viagens, os viajantes, também, se valiam de um guia, mas com outras funções, “[...] que lhes fornecia os rudimentos da língua, a descrição de rotas que conduziam às cidades e os lugares mais famosos” (Rejowski, 2002, p. 36).

Isto posto, no decorrer da história, não somente o guia de turismo se mostrava inovador. Os meios de transportes, em particular os terrestres, por meio do modal ferroviário evoluíam a passos largos, quando ocorreu aquela que foi considerada a primeira viagem 
organizada da história. Nesse sentido, atribui-se a Thomas Cook, nos idos do século XIX a função de primeiro agente de viagens do mundo.

Segundo larga bibliografia do turismo, em 1841, Thomas Cook realizou a primeira viagem turística no sentido mais próximo do que conhecemos atualmente. Se deslocou, com aproximadamente 570 pessoas, entre as cidades de Leicester e Lougboroug, Inglaterra (Ignarra, 1998, p. 18). Embora a referida viagem seja muito citada entre os autores do turismo (Ignarra, 1998; Montejano, 2001; Rejowski et al., 2002 \& Boyer, 2003; entre outros), efetivamente a primeira viagem turística (com o objetivo do lucro) ocorreu com Thomas Cook em 1845, composta por um itinerário de trem entre as cidades de Leicester, Nottingham e Derby para Liverpool, com taxas diferenciadas para a primeira e a segunda classes e com possibilidade para quem se interessasse, por meio de pagamento de taxa opcional, viajar de navio ao norte do País de Gales (Hintze, 2013).

Para consolidar essas viagens, Cook teria, dentre outras atividades, comercializado bilhetes, organizado os embarques e desembarques e praticado serviço de bordo, servindo alimentos e bebidas aos passageiros que buscavam um congresso de caráter religioso. Compreendendo que, assim se deu a origem do turismo moderno (Oliveira, 1998), qual seja, com base nos serviços prestados por Cook, estabelecem-se relações e semelhanças com as atribuições do profissional guia de turismo, notadamente com aquelas desenvolvidas pelo guia de deslocamento em viagens rodoviárias na contemporaneidade.

A partir dessa época, com o desenvolvimento de novas tecnologias, com a difusão dos meios de transportes e com uma organização laboral, dentre outras condições favoráveis, possibilitou-se os períodos de férias remuneradas e novas formas de lazer. Este também foi um período de muitas lutas em prol dos direitos dos trabalhadores e igualmente um momento de transição do capital no qual o trabalhador passa a cumprir a função de consumidor - e, com isso precisa de 'tempo livre' para poder consumir.

Nesse contexto, as atividades turísticas passaram a ser cada vez mais organizadas e, por consequência, demandaram formações específicas, tendo como exemplo a profissionalização do guia de turismo, considerado fundamental em se tratando da oferta derivada do turismo, que, conforme Beni (1998) é a oferta que reúne o conjunto de prestadores de serviços das empresas de turismo. 


\title{
3. APONTAMENTOS SOBRE A FORMAÇÃO PROFISSIONAL DO GUIA DE TURISMO
}

No Brasil, a formação profissional do guia de turismo remonta a meados do século passado. O Serviço Nacional de Aprendizagem Comercial (SENAC- SP) iniciou a oferta com cursos que tinham duração de quatro meses e carga horária de 180 horas e, para ingresso, bastava o aluno ter concluído o ensino fundamental, não havendo necessidade de formação em nível técnico para exercer a profissão. As disciplinas de Relações Humanas; Prevenção de Acidentes e Primeiros Socorros; Geografia e História Turística; Folclore, Tradição e Costumes; Noções de Arte e Estética e Excursões faziam parte da matriz curricular do curso (Celeste Filho, 2002). Nesses moldes, pontualmente, em 1965, o SENAC (SP) passou a ofertar o primeiro curso para formação profissional em guia de turismo que se tem notícia no Brasil (Della Monica, 2001).

De acordo com Montes (2013, p. 46,),

\begin{abstract}
Desde então o curso de guia de turismo passou por várias transformações. No ano de 1969, o SENAC/SP estruturou o curso Roteiro Turístico. Porém, com relação ao mercado de trabalho, em 1964 a mesma instituição realizou um Seminário de Guia de Turismo que teve por finalidade incentivar alunos universitários (oriundos de qualquer curso superior) a trabalharem nas férias escolares como guias pelo Brasil e Paraguai.
\end{abstract}

Nesse contexto, também, considera-se importante ressaltar a edição da Lei Federal no 5692/72, a qual fornecia os parâmetros para elaboração do currículo do ensino de $2^{\circ}$ grau aliado a uma habilitação profissional. Em outras palavras, compulsoriamente, induzia os alunos cursar o ensino profissionalizante. A profissionalização deveria prevalecer sobre a educação geral. Sequencialmente, o Parecer $n^{\circ}$. 45/72 estabeleceu 130 cursos técnicos, dentre os quais constavam os cursos de Hotelaria e Turismo (Cunha, 2005).

Entretanto, a habilitação de guia de turismo não estava entre os cursos sugeridos. Isso tudo ocorria em um momento que um dos destinos procurados, em especial, passou a ser Orlando, na Flórida (EUA). Os turistas seguiam em busca das atrações da Walt Disney Company. Para atender a essas novas demandas, o segmento de agências enveredou-se para tal fim. Logo, houve urgência e necessidade de profissionais para execução desses roteiros (Montes, 2013).

Todavia, não havia cursos suficientes para formação profissional (no setor privado) que suprissem à demanda, tampouco no setor público em função da ausência de oferta para habilitação do Guia e Turismo. No bojo desses acontecimentos, a formação profissional continuava sendo ofertada pela iniciativa privada, por meio do SENAC, e ao setor público 
cabia seus cadastramentos por meio da, então, Empresa Brasileira de Turismo $\left(\right.$ EMBRATUR $\left.^{1}\right)$.

Ademais, nesse período, as atividades que concerniam aos guiamentos eram desenvolvidas, em sua maioria, por agentes de viagens, pois não havia profissionais em número e com formação suficiente para as funções. Esses acompanhantes “[...] divertiam-se tanto quanto os clientes que adquiriam um pacote de viagem, sendo muitas vezes difícil de distingui-los dos passageiros" (Carvalho, 2003, p. 20).

Porém, essa realidade não perdurou, de modo que, por meio da Lei nº. 8623/93, Decreto Lei nº 946/93, seguidas por quatro Deliberações Normativas ${ }^{2}$, se deu início à regulamentação da profissão ${ }^{3}$. Assim, os Guias passaram a ser cadastrados a partir da conclusão de seus cursos de formação, salvo para aqueles profissionais que foram amparados pela lei, os quais já atuavam na profissão e/ou se encontravam de acordo com as alíneas b e c do $\S 3^{\circ}$, Decreto Lei no. 946/93, como se seguem:

b) tenha concluído o curso de formação profissional à distância, e sido aprovado em Exame de Suplência Profissionalizante ministrado pelo Serviço Nacional de Aprendizagem Comercial - SENAC; ou

c) comprove, no prazo de 180 dias de vigência deste Decreto, o efetivo exercício da profissão por, no mínimo, dois anos, bem como aprovação em Exame de Suplência nos termos da alínea anterior.

Outra menção legal que amparou profissionais que já exerciam de alguma forma atribuições específicas de guiamento turístico foi exposta na Deliberação Normativa $n^{\circ}$. 326/94, da seguinte forma:

Art. $1^{\circ}$ - Recomendar aos Órgãos Oficiais de Turismo, das Unidades da Federação que, em complemento à legislação federal de turismo em vigor, estabeleçam normas próprias para cadastro, classificação, controle e fiscalização de prestadores de serviços, não abrangidos na referida legislação federal.

Parágrafo Único - As normas a serem estabelecidas, na forma deste artigo, deverão referir-se, prioritária e especialmente, às pessoas físicas prestadoras de serviços turísticos, cuja atuação profissional, destinada a atender peculiaridades específicas do patrimônio e da infra-estrutura [sic] turísticas locais, tenha significativa implicação na qualidade dos produtos turísticos estaduais oferecidos.

Art. $2^{\circ}$ - Considerar-se-ão incluídos no disposto no artigo anterior, entre outras, as pessoas físicas cuja prática, decorrente do tempo de vivência e experiência em

\footnotetext{
${ }^{1}$ EMBRATUR - Instituto Brasileiro de Turismo desenvolve atualmente atividades de promoção e marketing. “[...] é a autarquia especial do Ministério do Turismo responsável pela execução da Política Nacional de Turismo no que diz respeito a promoção, marketing e apoio à comercialização dos destinos, serviços e produtos turísticos brasileiros no mercado internacional". (http://www.turismo.gov.br/institucional/2015-04-06-14-28-40.html).

${ }^{2}$ Deliberações Normativas: $n^{\circ}$. 326/1994, 425, 426 e 427/2001, arroladas na confecção deste artigo no que concerne à pertinência dos apontamentos.

${ }^{3}$ Passando ser a única profissão regulamentada no Turismo.
} 
determinado atrativo ou empreendimento turístico, próprio de certa região, lhes permita conduzir o turista, com segurança, em seus passeios e visitas, ao local, prestando-lhes orientação e informação específica e tornando mais atrativa sua programação.

Parágrafo Único - Estão compreendidas neste artigo as pessoas físicas que conduzam e orientam o turista em passeios e visitas realizados no interior de determinado atrativo ou empreendimento turístico localizado:

a) na selva amazônica, pantanal, parques nacionais, ou a outros locais em equilíbrio ambiental;

b) em dunas, cavernas ou outros atrativos ecológicos específicos;

c) em locais de atrativos náuticos;

d) em empreendimento considerado de valor histórico e artístico, pelas autoridades governamentais competentes.

Os demais profissionais deveriam apresentar certificações (habilitações), as quais, num primeiro momento, conforme redação do Decreto Lei $n^{\circ} .946 / 93, \quad$ estariam a cargo, exclusivamente, do Serviço Nacional de Aprendizagem Comercial (SENAC-SP).

Ao consultar a Lei Federal nº $8623 / 93$ verifica-se em seu Art. $1^{\circ}$ que:

É considerado Guia de Turismo o profissional que, devidamente cadastrado na EMBRATUR - Instituto Brasileiro de Turismo, nos termos da Lei $\mathrm{n}^{\circ}$ 8.623, de 28 de janeiro de 1993, exerça as atividades de acompanhamento, orientação e transmissão de informações a pessoas ou grupos, em visitas, excursões urbanas, municipais, estaduais, interestaduais, internacionais ou especializadas.

Também, se verifica no Art. $4^{\circ}$ do Decreto Lei $n^{\circ}$. 8623/93, especialidades da formação profissional e das atividades a ser desempenhadas que deveriam ser comprovadas perante a EMBRATUR, podendo os Guias de Turismo ser cadastrados, como se seguem:

I - guia regional - quando suas atividades compreenderem a recepção, o traslado, o acompanhamento, a prestação de informações e assistência a turistas, em itinerários ou roteiros locais ou intermunicipais de uma determinada unidade da federação, para visita a seus atrativos turísticos;

II - guia de excursão nacional - quando suas atividades compreenderem o acompanhamento e a assistência a grupos de turistas, durante todo o percurso da excursão de âmbito nacional ou realizada na América do Sul, adotando, em nome da agência de turismo responsável pelo roteiro, todas as atribuições de natureza técnica e administrativa necessárias à fiel execução do programa;

III - guia de excursão internacional - quando realizarem as atividades referidas no inciso II, deste artigo, para os demais países do mundo;

IV - guia especializado em atrativo turístico - quando suas atividades compreenderem a prestação de informações técnico-especializadas, sobre 
determinado tipo de atrativo natural ou cultural de interesse turístico, na unidade da federação para o qual o mesmo se submeteu a formação profissional específica.

Ademais, no Art. $5^{\circ}$ do Decreto acima citado verifica-se que os Guias de Turismo poderão ser cadastrados em uma ou mais classes, desde que comprovada a formação especifica para cada habilitação.

Após seis anos da edição da referida Lei e do Decreto que regulamentou a profissão do Guia de Turismo no Brasil,

todos os profissionais foram oficialmente convocados por meio de Diário Oficial da União pela EMBRATUR para oficializarem seu cadastramento de acordo com a Lei no. 8.623/93. Essa convocação teve o prazo de 24 meses para garantir que todos os guias de turismo fossem efetivamente recadastrados. (Montes, 2013)

Nessa época, para o efetivo cadastro, conforme estabelecido pela EMBRATUR, os candidatos deveriam se submeter aos cursos oficialmente ofertados, com cargas horárias de 400h e 550h, respectivamente para as habilitações de guias para atuação em âmbito regional e internacional. Dessa maneira, percebe-se uma carga horária a ser cumprida bem maior que aquela dos anos de 1960, chegando a triplicar o tempo exigido para formação. No início dos anos de 2000, tais informações passaram a fazer parte do conteúdo da Deliberação Normativa $n^{\circ} .427 / 2001^{4}$, além do apontamento de uma grade curricular específica para a formação de nível médio técnico (Carvalho, 2003).

Além do mais, para Carvalho (2003), os cursos passaram a ser ofertados com duração entre 18 e 36 meses, em escolas públicas e privadas, com vistas ao aprendizado teórico-prático, ao acompanhamento de passageiros e às noções sobre relações interpessoais, em um contexto relacionado a duas grandes áreas do conhecimento: ciências humanas e sociais e as ciências sociais aplicadas.

No tocante ao mercado, a formação ofertada pelos cursos em questão, acompanharam as demandas oriundas das atividades turísticas com vistas à qualidade na prestação de serviços à operacionalização de roteiros turísticos, face às exigências do mercado, diante de um campo profissional com uma oferta de profissional relativamente baixa, que desde os anos de 1960 vinha, constantemente, passando por reformulações.

No ano de 2008, o Catálogo Nacional de Cursos Técnicos ${ }^{5}$ (CNTC), editado por meio da Resolução CNE/CEB nº. 03/2008, dentre outros assuntos, tratou da desfragmentação dos cursos técnicos em Turismo. Sete cursos foram lançados, sendo estes: Técnico em

\footnotetext{
${ }^{4}$ Revogada em 2014, por meio da Portaria Ministerial no 027 (MTur).

${ }^{5}$ Disponível em: http://portal.mec.gov.br/catalogo-nacional-de-cursos-tecnicos. Acesso em: 14.04.2016.
} 
Agenciamento de Viagem; Técnico em Cozinha; Técnico em Eventos; Técnico em Guia de Turismo; Técnico em Hospedagem; Técnico em Lazer; Técnico em Serviços de Restaurante e Bares.

Esses cursos passaram a ser ofertados, nas modalidades: médio integrado e/ou subsequente (para estudantes que já haviam concluído o ensino médio). Passaram a ser ofertados em escolas das redes estaduais de educação, assim como em escolas técnicas vinculadas a essas instituições, nos Institutos Federais de Educação em todo o país e, também, pelas unidades do Serviço Nacional de Comercial (SENAC). Havia uma tendência da oferta de cursos para a formação de Guia Regional pelas redes estadual e Guia Regional e/ou de cursos para formação de Guia Excursão Nacional/América do Sul pelas demais instituições citadas. Em relação aos cursos de formação do Guia de Turismo Internacional, historicamente, vem sendo ofertados, em sua maioria, por instituições privadas, de forma presencial, e, também, na modalidade de ensino à distância (EAD), não diferente das ofertas para formações em outras categorias, sendo ofertadas, em sua maioria, por instituições privadas.

Seguindo o caminho da formação profissional, no que concerne aos processos legais para oferta dos cursos técnicos, em síntese, em um primeiro momento, as Deliberações Normativas n. 426 e 427, ambas de 2001, versaram sobre as exigências para a oferta dos referidos cursos, em consonância com a Lei Federal nº 8623/93. Com base nesses documentos, tais incumbências, até 2003, estavam a cargo da EMBRATUR, que por sua vez emitiam pareceres que autorizavam a oferta dos cursos em questão. Mas, com a criação do Ministério do Turismo (MTur), essas incumbências se deslocaram para o âmbito das suas competências e aos seus órgãos delegados. Nesse contexto, havia uma duplicidade de atribuições, as quais foram desmembradas por meio da Nota Técnica $n^{\circ}$ 034/2010 reordenando questões legais, do ponto de vista de parecer, autorização e reconhecimento dos cursos técnicos para formação do Guia de Turismo, que foram reiterados pela Portaria Ministerial $\mathrm{n}^{\mathrm{o}} 027 / 2010^{7}$ (MTur), Art. 15, da seguinte forma:

$\S 2^{\circ}$ A competência para a apreciação e a aprovação do mérito dos planos de curso para a formação de técnicos em Guia de Turismo a serem ministrados pelas

\footnotetext{
${ }^{6}$ A qual corrigiu um erro estrutural da Portaria Ministerial $n^{\circ}$. 07/2005, notadamente, quando isentava o MTur das incumbências de emissões de pareceres para autorização dos cursos técnicos de formação profissional e, ainda, não indicava quais seriam as instituições responsáveis para tal fim.

${ }^{7}$ No âmbito das contribuições trazidas pela mencionada Portaria, considera-se, também, importante ressaltar, a possibilidade estágio ao final do processo de formação, versada no documento, em seu Art. 15, no parágrafo $5^{\circ}$, da seguinte forma: "O estágio supervisionado, quando for o caso, dos alunos concludentes dos cursos técnicos de formação profissional de guia de turismo, deverá ser orientado por Guia de Turismo credenciado e em situação regular". Face ao exposto, verifica-se que, pela primeira vez, um documento oficial versa sobre a questão.
} 
instituições de ensino no país fica a cargo exclusivamente dos conselhos de educação e órgãos do sistema educacional.

$\S 3^{\circ}$ Somente terão validade, para fins de cadastro junto ao Ministério do Turismo, os cursos de qualificação, habilitação e especialização profissional desenvolvidos no nível técnico, obedecida a carga horária mínima estipulada pelo Ministério da Educação.

A estipulação de carga horária mínima exigida (800h) e demais questões pertinentes, como por exemplo 'os itinerários formativos', a partir de 2008, passaram obedecer ao exposto no Catálogo Nacional de Cursos Técnicos (CNTC), observadas as especificações contidas no Eixo Tecnológico de Turismo, Hospitalidade e Lazer, que dentre os sete cursos abarcados, conforme já mencionado, se ateve, também, ao Curso Técnico em Guia de Turismo.

Nos desdobramentos das políticas, no que tange à formação do profissional de guiamento, em 2011, o Programa Nacional de Acesso ao Ensino Técnico e Emprego $\left(\right.$ PRONATEC $^{8}$ ), elaborado por meio da Lei no 12513 lançaram-se 288 cursos em várias áreas, com uma proposta de formação com carga horária de 160 a 300 horas, no âmbito das capacitações. Dentre os lançamentos, no que tange às atividades turísticas, se encontravam os cursos de: Auxiliar de Agenciamento de Viagens, Camareira em Meios de Hospedagem, Recepcionista em Meios de Hospedagem, Condutor de Visitantes, Recepcionista de Eventos, Recepcionista de Turismo Rural, Agente de Informações Turísticas e Monitor de Recreação. Notadamente, os cursos de Condutor de Visitantes e Agente de Informações Turística, no tocante às atribuições, conflitaram, em parte considerável, com as funções do Guia de Turismo.

No entanto, do ponto de vista legal, as funções desenvolvidas por esses profissionais estariam em 'zona nebulosa' em relação à legislação, em detrimento às funções do guia de turismo, as quais são amparadas legalmente por meio dos documentos que regulamentam a profissão. Tal impasse ainda perdura à atualidade, carecendo de um olhar mais comprometido das autoridades competentes. Todavia, a Portaria Ministerial $n^{\circ}$. 027/2014, ao menos, em parte, no que se refere ao Condutor, dirimiu algumas dúvidas do impasse que foi ocasionado pela sua oferta, assim como versou sobre monitor, conforme o exposto a seguir:

Art. $8^{\circ} \mathrm{A}$ atividade de guia de turismo não se confunde com o exercício das atividades de condutor de visitantes em unidades de conservação federais, estaduais ou municipais e de monitor de turismo.

${ }^{8}$ O programa teve como objetivo "expandir, interiorizar e democratizar a oferta de cursos técnicos e profissionais de nível médio e cursos de formação inicial e continuada para trabalhadores” (BRASIL, 2011). 
$\S 1^{\circ}$ Nos termos da legislação pertinente, considera-se condutor de visitantes em unidades de conservação o profissional que recebe capacitação específica para atuar em determinada unidade, cadastrado no órgão gestor, e com a atribuição de conduzir visitantes em espaços naturais e/ou áreas legalmente protegidas, apresentando conhecimentos ecológicos vivenciais, específicos da localidade em que atua, estando permitido conduzir apenas nos limites desta área.

$\S 2^{\circ}$ Considera-se monitor de turismo a pessoa que atua na condução e monitoramento de visitantes e turistas em locais de interesse cultural existentes no município, tais como museus, monumentos e prédios históricos, desenvolvendo atividades interpretativas fundamentadas na história e memória local, contribuindo para a valorização e conservação do patrimônio histórico existente, não sendo permitido ao monitor de turismo a condução de visitantes fora dos limites do respectivo local.

$\S 3^{\circ}$ A necessidade ou obrigatoriedade de acompanhamento de condutor durante visitações deverá ser verificada pelo guia de turismo que se deslocar com o grupo de turistas a uma determinada unidade de conservação.

Considera-se relevante e oportuna a menção da Portaria Ministerial nº. 027/0214, no que se refere ao Monitor e Condutor, aclarando suas funções, que se apresentam de forma complementar as práticas profissionais do guia de turismo, mas não estavam muito bem definidas e, comumente, vinham sendo objetos de discussões entre esses profissionais. Ademais, um ponto positivo foi que deixou clara a interdependência entre as funções, havendo necessidade, em determinados momentos, da contratação complementar dos serviços desses profissionais para execução de atividades pontuais. Com efeito, isso vem contribuir com o relacionamento entre os profissionais e, consequentemente, na qualidade de seus serviços.

Em se tratando da qualidade dos serviços e como este componente versa sobre a satisfação dos turistas, assim como no fator confiança e segurança, há que se notar dois estudos internacionais, que obtiveram resultados positivos sobre o papel do guia de turismo para a satisfação dos turistas.

\section{QUESTÕES LEGAIS SOBRE A PROFISSÃO DO GUIA DE TURISMO: OUTROS APONTAMENTOS}

Retomando os apontamentos históricos, no que tange às questões legais, em 2003, com a criação do Ministério do Turismo, novas ações foram colocadas em práticas para ordenamento da atividade turística nacional. Nesse momento da história, considera-se importante voltar a destacar que as incumbências do cadastramento do Guia de Turismo não mais estariam sob responsabilidade da EMBRATUR ${ }^{9}$.

${ }^{9}$ Deste então, o cadastro passou a ser realizado pelo MTur, via Cadastur. 
No bojo das ações (em curso) do início do terceiro milênio, com destaque para a edição da Lei Geral do Turismo (LGT) no . 11771, a partir da qual se criou um sistema de cadastro obrigatório para prestadores de serviços que atendem ao turismo, denominado Cadastur $^{10}$. Sistema este que, além de cadastrar os profissionais Guias de Turismo, passou a cadastrar empresas como: agências de turismo, meios de hospedagem (albergue, condo-hotel, flat, hotel urbano, hotel de selva, hotel fazenda, hotel histórico, pousada, resort e cama \& café) transportadoras turísticas, acampamentos turísticos, organizadoras de eventos e parques temáticos foram abarcadas pela citada lei, assim como a atividade profissional do Guia de Turismo.

O sistema inédito, até então no Brasil, se apresentou como uma ferramenta que facilitou sobremaneira a verificação aos cadastros dos equipamentos e serviços arrolados. Em relação aos profissionais Guias de Turismo, legalmente cadastrados ${ }^{11}$, contribuiu para a verificação dados, dentre outras informações: seus contatos, suas categorias profissionais e a unidade da federação que se encontram cadastrados, que conforme suas formações revelam suas áreas de atuações, seja o Guia Turismo Regional, Guia de Excursão Nacional/América do Sul, Guia de Excursão Internacional ou Guia Especializado em Atrativo Turístico.

Seguindo a linha do tempo dos acontecimentos, em 2014, foi editada a Portaria Ministerial $n^{\circ} 27$, último documento oficial sobre a profissão do Guia de Turismo no Brasil. No que tange às áreas de atuações, retifica pontos da Lei $n^{\circ} .8623 / 93$ e do Decreto Lei $n^{\circ}$ 946/93, além do seu Art. 26 expor que "ficam revogadas as disposições das Deliberações Normativas $n^{\circ}$. 426, de 4 de outubro de 2001, e 427, de 4 de outubro de 2001, naquilo em que forem incompatíveis ou conflitantes com a presente Portaria”.

Ademais, retifica de forma mais clara as áreas de abrangências de cada uma das categorias. Em outras palavras, o profissional Guia de Turismo Regional que possui habilitação para atuar em determinado estado, não possui autorização para Guiar em outro. Por exemplo, um Guia de Turismo Regional Paraná não possui autorização para guiamentos no estado de São Paulo, e vice e versa. Para tanto, precisaria cursar o Curso Técnico em Guia de Turismo, categoria Regional, ofertado naquele estado e requerer cadastramento para desempenhar suas funções naquela região. Também, considera-se relevante mencionar que,

\footnotetext{
${ }^{10}$ Cadastur é o sistema de cadastro de pessoas físicas e jurídicas que atuam no setor de turismo. O cadastro garante diversas vantagens e oportunidades de negócios aos seus cadastrados e é também uma importante fonte de consulta para o turista. O programa é executado pelo Ministério do Turismo em parceria com os órgãos oficiais de turismo nos 26 estados e no (http://www.cadastur.turismo.gov.br/cadastur/SobreCadastur.mtur)

${ }^{11}$ Com base na 197/2013, a renovação do cadastro de guia de turismo passou a ocorrer de dois para cada cinco anos, devendo o interessado solicitá-la via Cadastur. Dessa forma, ficou revogado o prazo, anteriormente, estabelecido por meio da Deliberação n 426/2001.
} 
para o Guia de Turismo Regional é vedada, conforme a Portaria Ministerial $\mathrm{n}^{\circ}$. 027/0214 (MTur), transpor fronteiras do estado em que está cadastrado, pois dessa forma estaria desempenhando ilegalmente suas funções, visto que é uma atribuição do Guia de Turismo Nacional.

Sobre a categoria Guia de Turismo Especializado em Atrativos Naturais ou Culturais, que em um primeiro momento, de acordo com EMBRATUR, por meio da Lei $\mathrm{n}^{\circ}$. 8623/93 teve a função de recepção e o acompanhamento de visitantes em locais como museus, sítios históricos, parques nacionais, entre outros, foi mencionada na Portaria Ministerial $n^{\circ} .027 / 0214$, com a seguinte redação:

Guia Especializado em Atrativo Turístico - quando suas atividades compreenderem a prestação de informações técnico-especializadas sobre determinado tipo de atrativo natural ou cultural de interesse turístico, na unidade da federação para qual o profissional se submeteu à formação profissional específica. (Art. $3^{\circ}, \S$ IV)

Art. $4^{\circ}$ Para requerer o cadastro na categoria de Guia de Turismo especializado em atrativo natural ou em atrativo cultural, o interessado deve, primeiramente, ser habilitado como guia de turismo regional, em cursos específicos de qualificação profissional.

Parágrafo único. A atividade de Guia Especializado em Atrativo Natural ou atrativo cultural somente poderá ser exercida por aquele que tiver formação profissional específica para o Estado do atrativo turístico no qual atuará.

Conforme a redação da Portaria mencionada, para requerer cadastramento Guia Especializado em Atrativo Turístico, o profissional, necessariamente deverá estar habilitado como Guia Regional na unidade da federação onde pretende atuar, requisito não verificado no Decreto no . 946/93. Além do mais, o documento cita que, na ausência desse profissional, o Guia Regional deverá substituí-lo.

Nesse sentido, considera-se relevante ressaltar que "[...] as especificidades de cada uma dessas funções referem-se ao conjunto de atribuições que determinam a importância do Guia de Turismo em cada um de seus grupos de visitantes”. (Montes, p. 50, 2013).

Isto posto, depreende-se que as especificidades expostas nos documentos oficiais vêm ao encontro da diversidade de funções que competem ao Guia de Turismo e suas respectivas categorias. Aliás, essas especificidades vêm ao encontro das segmentações e tipologias turísticas. Ao pensar o turista atual, menos homogêneo que o turista de massa (maior segmentação de mercado capitalista), compreende-se que há uma demanda cada vez mais acentuada em busca de um profissional de guiamento que possua conhecimentos da área que abrange sua habilitação e jurisdição, além de conhecimentos técnicos, inteligência emocional, capacidade de verbalizar o que sabe saber, integradas às condutas morais e éticas, 
com vistas às experiências turísticas contemporâneas, nos horizontes de um turismo responsável.

\section{CONSIDERAÇÕES FINAIS}

Os apontamentos históricos demonstram que as atividades dos guias, desde a antiguidade, convertem em uma série de funções. Em um primeiro momento, depreende-se que ora se diferencia e que ora se aproxima das atribuições dos guias de turismo contemporâneos. Isso leva a compreensão de que o volume de atribuições, historicamente, sempre acompanharam os afazeres desses profissionais. Se por um lado, há um número elevado de atribuições ao exercício da profissão, de outro, no campo da legalidade, não se observa tal volume.

Extrapolando essa situação, o guia de turismo efetivamente cadastrado e regulamentado precisa disputar seu espaço com outros 'profissionais' que atuam sem a devida credenciação, isto é, em desconformidade com a legislação.

Ainda, a respeito de questões legais, considera-se relevante ressaltar duas delas. A primeira de no sentido de deixar claro as incumbências da EMBRATUR e do Ministério do Turismo, notadamente no que concerne ao cadastramento dos Guias de Turismo, que até a criação do Ministério, em 2003, era competência da EMBRATUR. Pode parecer simples essa informação, mas na prática, para alguns profissionais, observa-se incompreensões sobre as competências de tais órgãos governamentais. A segunda questão se trata das funções dos monitores e condutores em atividades turísticas que, anterior à edição da Portaria Ministerial $n^{\circ}$ 027/2014, se encontram em desentendimento, pois, não era incomuns dúvidas em relação às atribuições desse profissional.

Até aqui, buscou-se fazer um balanço histórico da profissão do guia de turismo. Nesse contexto, entende-se que nenhum levantamento do passado se justifica se não for para conduzir um futuro melhor, no caso específico deste trabalho, numa melhor condição para o Guia de Turismo profissional e, por conseguinte, trade como um todo, haja vista a importância do profissional Guia de Turismo.

Para além de toda a problemática apontada neste artigo considera-se importante mencionar que, especialmente, frente às demandas contemporâneas do turismo, não apenas as exigências meramente 'mercadológicas' de atuação, pode-se afirmar que o profissional de guiamento começa a perceber seu espaço sendo ameaçado em direções diversas. Ademais, para além das questões de legislação, pode-se analisar outras demandas que exigem do profissional em questão sua atualização: o Guia já não é mais o 'detentor' exclusivo das 
informações sobre os lugares. O advento da internet democratizou a informação e o turista atual as detém com maior facilidade. A exemplo disso, dentre outras, tem-se as plataformas de turismo colaborativo, como a Rent a Local Friend.

Também, pode-se perceber que as demandas do turista não são mais 'apenas' por informações, mas por, efetivamente, conhecer os locais que visitam de modo a gerar uma experiência por meio do turismo, além de facilitar tal experiência. Nesse contexto, somente transmitir informações, competência a qual muitos guias ainda insistem em considerar como a mais importante função de sua profissão, já não basta.

Dessa forma, é fato que se faz necessário formação em Curso Técnico de Guia de Turismo e estar devidamente legalizado, todavia a formação deve estar inclinada para as demandas contemporâneas, pois somente o título sem competências adequadas à realidade hodierna são insuficientes para seu desempenho.

Nesse sentido, após realização destas análises da situação da legislação e formação dos guias, procurou-se contribuir com as próximas ofertas de cursos de capacitação de guias de turismo com algumas sugestões: as atribuições do profissional guia de turismo podem ser consideradas como uma das mais relevantes das atividades turísticas, em função do grau de aproximação, isto é, nas interações humanas e aos demais elementos inerentes à composição dos roteiros, pontualmente, no que tange ao seu papel como facilitador e mediador (Hintze, 2007). Facilitador no tocante aos produtos, atrativos, infraestrutura, equipamentos e serviços, em relação às facilitações para consumo e utilização destes. Como mediador, pontuam-se as relações interpessoais e profissionais, notadamente, no que concernem as relações entre organizadores, tripulação e turistas e, não menos importante na delicada relação entre visitantes e visitados. Entretanto, face as motivações do turista atual com inclinação às vivências e experiências turísticas, o guia pode ser um diferencial ao operacionalizar com propriedade os roteiros. Caso contrário, tais anseios e expectativas podem não se concretizar e, ainda, impactar na concepção do turista em relação ao local visitado e na sua imagem como destino.

Sobre a formação profissional, apurou-se que, em um primeiro momento, a formação se deu por meio da iniciativa privada e que, paulatinamente, passou a ser objeto da educação profissional ofertada pelas redes estaduais e federais de educação, todavia a necessidade de convergência em se tratando das competências face as reais demandas contemporâneas, nos horizontes das experiências turísticas contemporâneas, carecem.

Por fim, percebe-se que, ainda, há muito o que fazer a respeito da profissão Guia de Turismo: no campo das políticas em educação, da legislação profissional, do mundo do 
trabalho e da pesquisa. Nesse caminho, em se tratando deste artigo, acredita-se que sua contribuição foi, com um olhar ao passado, compilar apontamentos históricos que possam servir de subsídios para reflexões do presente e vislumbrar perspectivas à profissão.

\section{REFERÊNCIAS}

Beni, M. (1998). Análise Estrutural do Turismo. São Paulo: SENAC.

Brasil. Decreto Federal $n^{\circ}$ 946, de 1 de outubro de 1993. Regulamenta a Lei $n$. 8.623, de 28 de janeiro de 1993, que dispõe sobre a profissão de Guia de Turismo. Recuperado em 01 de fevereiro, 2017 de http://www.planalto.gov.br/ccivil_03/decreto/Antigos/D0946.htm.

Brasil (2017). Ministério do Turismo. Legislação. Recuperado em 14 de abril, 2017 de http://www.turismo.gov.br/legislacao/?p=135.

Brasil (2017). Ministério do Turismo. Cadastur. Recuperado em 14 de abril, 2017 de http://www.cadastur.turismo.gov.br/cadastur/SobreCadastur.mtur.

Brasil (2015). Ministério do Turismo. Institucional. Recuperado em 14 de abril, 2017 de http://www.turismo.gov.br/institucional/2015-04-06-14-28-40.html.

Brasil (1993). Lei $\mathrm{n}^{\circ}$ 8.623, de 28 de janeiro de 1993. Dispõe sobre a profissão de Guia de Turismo. Recuperado em 01 de fevereiro, 2017 de http://www.planalto.gov.br/civil_03/Leis/L8623.html.

Brasil (2017). Ministério da Educação e Cultura (MEC). Catálogo Nacional de Cursos Técnicos. Recuperado em 14 de abril, 2017 de http://catalogonct.mec.gov.br/catalogo.pdf.

Brasil (2014). Ministério do Turismo. Portaria $n^{o}$ 27: Estabelece requisitos e critérios para o exercício da atividade de Guia de Turismo e dá outras providências. Diário Oficial da União, Brasília, DF, Seção 1, p. 110-111.

Brasil (2010). Nota Técnica Ministerial nº 007/2010. Ministério do Turismo, Brasília, DF.

Brasil (2010). Nota Técnica Ministerial nº 034/2010. Ministério do Turismo, Brasília, DF.

Carvalho, P. J. (2003). Condução de grupos Turísticos. São Paulo: Chronos.

Celeste Filho, M.(2002). A institucionalização do turismo como curso universitário (décadas 1920-1930). 120 f. Dissertação (Mestrado em Educação) - Pontifícia Universidade Católica de São Paulo. PUC/SP.

Chang, K. (2014). Examining the Effect of Tour Guide Performance, Tourist Trust, Tourist Satisfaction, and Flow Experience on Tourists' Shopping Behavior. Asia Pacific Journal of Tourism Research, 19(2), 219-247.

Cunha, L. A. (2005). O ensino profissional na irradiação do industrialismo. São Paulo: Editora da UNESP. 
Della Monica, L. (2001) Turismo e folclore: um binômio a ser cultuado. $2^{\text {a }}$ edição. São Paulo: Global.

Hintze, H. C. (2007). Guia de turismo: formação e perfil profissional. São Paulo: Roca.

Hintze, H. C. (2013). Espetáculos e invisibilidades do discurso legitimador do turismo. $537 \mathrm{f}$. Tese (Doutorado em Ecologia Aplicada) - Ecologia de Agroecossistemas, Universidade de São Paulo, USP.

Huang, S; Hsu, C. H. C \& Chan, A (2010). Tour Guide Performance and Tourist Satisfaction: a Study of the Package Tours in Shanghai. Journal of Hospitality \& Tourism Research, 34(1), 3-33.

Ignarra, L. R. (2013). Fundamentos do Turismo. $3^{\text {a }}$ edição. São Paulo: Editora SENAC.

Montes, V. (2013). Saberes profissionais do Guia de Turismo: passeios etnográficos pela profissão. 272 f. Tese (Doutorado em Educação) - Universidade Federal da Bahia. UFBA.

Oliveira, D. (1998). Turismo e Consumo: a quarta geração turística. In: GASTAL, S. (org.) Turismo: nove propostas para um saber-fazer. Porto Alegre: Edelbra.

UNWTO - World Tourism Organization (2017). Tourism Towards 2030. Recuperado em 19 de agosto, 2017 de http://www2.unwto.org/.

Senac, DN (2002). Turismo no Brasil: um guia para o guia. Coord: Alexandre Raposo et al. Rio de Janeiro: Ed. Senac Nacional.

Sales, S. (2012). Teoria, planejamento e prática de guia. Fortaleza: IFCE.

Rejowski, M. (2002). Turismo no percurso do tempo. São Paulo: Aleph.

Salgueiro, V. (2002). Grand Tour: uma contribuição à história do viajar por prazer e por amor à cultura. Revista Brasileira de História (Impresso), 22(44), 289-310. São Paulo.

Sigaux, G. (1965) History of tourism. Londres: Leisure Arts. 